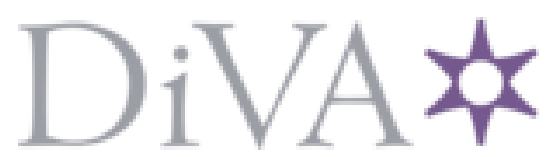

http://www.diva-portal.org

This is the published version of a paper presented at The 2015 ACM International Joint Conference on Pervasive and Ubiquitous Computing (UbiComp 2015), Osaka, Japan, September 7-11, 2015.

Citation for the original published paper:

Åström, J., Ruoppila, S., Ertiö, T., Karlsson, M., Thiel, S-K. (2015)

Potentials and challenges of a living lab approach in research on mobile participation.

In: Kenji Mase, Marc Langheinrich \& Daniel Gatica-Perez (ed.), UbiComp/ISWC'15 Adjunct:

Adjunct Proceedings of the 2015 ACM International Joint Conference on Pervasive and Ubiquitous

Computing and Proceedings of the 2015 ACM International Symposium on Wearable Computers

(pp. 795-800). New York: ACM Press

http://dx.doi.org/10.1145/2800835.2804399

N.B. When citing this work, cite the original published paper.

Permanent link to this version:

http://urn.kb.se/resolve?urn=urn:nbn:se:oru:diva-47731 


\section{Potentials and Challenges of a Living Lab Approach in Research on Mobile Participation}

\author{
Joachim Åström \\ Örebro University, Sweden \\ Fakultetsgatan 1, 70182 Örebro, \\ Sweden \\ joachim.astrom@oru.se \\ Sampo Ruoppila \\ Titiana Ertiö \\ University of Turku, Finland \\ 20014 Turun yliopisto, Finland \\ sampo.ruoppila@utu.fi \\ titiana.ertio@utu.fi \\ Martin Karlsson \\ Örebro University, Sweden \\ Fakultetsgatan 1, 70182 Örebro, \\ Sweden \\ martin.karlsson@oru.se

\section{Sarah-Kristin Thiel} \\ FTW Telecommunications Research \\ Centre Vienna, Austria \\ Donau-City-Straße 1, 1220 Wien \\ thiel@ftw.at
}

Permission to make digital or hard copies of all or part of this work for personal or classroom use is granted without fee provided that copies are not made or distributed for profit or commercial advantage and that copies bear this notice and the full citation on the first page. Copyrights for components of this work owned by others than ACM must be honored. Abstracting with credit is permitted. To copy otherwise, or republish, to post on servers or to redistribute to lists, requires prior specific permission and/or a fee. Request permissions from

Permissions@acm.org.

Ubicomp/ISWC '15 Adjunct, September 7-11, 2015, Osaka, Japan. Copyright 2015 O ACM 978-1-4503-3575-1/15/09,\$15.00. http://dx.doi.org/10.1145/2800835.2804399

\begin{abstract}
This paper discusses potentials and challenges of living lab approach in studying pervasive mobile participation, including reporting experiences of a living lab experiment currently conducted in Turku, Finland. It shows that the living lab approach offers both new opportunities and challenges when implemented in the urban governance context. In general, living labs hold great potential for researching participatory processes enabled by state-of-the-art technology in real world contexts. However, conducting experiments in those real life contexts presents a number of inherent difficulties that makes the potential essentially vulnerable, such as usability issues and political ambivalence on change.
\end{abstract}

\section{Author Keywords}

Pervasive Participation; Living Labs; Stakeholder Engagement; Urban Governance; Mobile Participation.

\section{ACM Classification Keywords}

H. 5 INFORMATION INTERFACES AND PRESENTATION (e.g., HCI); J.4 SOCIAL AND BEHAVIORAL SCIENCES; K.4 COMPUTERS AND SOCIETY 


\section{What is a living lab approach?}

Following $[2,3]$, in this paper a living lab approach refers to innovations being studied and tested in real-life contexts with real users. Following this approach, the research data is collected primarily through the living lab.

\section{Introduction}

Many citizens have become critical of how their democracies work, and begun to demand improved democratic performance. At the same time, political participation is shifting from traditional forms, such as elections and parties, to more direct, individualised forms of political expression [1]. In the face of this development, many governments are searching for participatory innovations that help reconnect representative institutions and their constituents. The affordances of digital technologies put electronic participation at centre stage of these debates. However, much research is still required on which emerging technologies will actually work in what reallife political contexts.

In democracy studies, many researchers focus on already established phenomena, usually telling policy makers where they went wrong. The innovative attempts to institute some version of civic governance are few in number. Furthermore, the solutions used for engaging citizens are rarely based on the latest - or most suitable - technologies. Some other scholars, technical and social alike, are conducting small-scale experiments. However, these traditional lab experiments are usually designed for answering specific questions in controlled environments, e.g. the micro dynamics of online public deliberation or usability of technical features. Overall there seems to be little research on how to develop high-tech solutions in multifaceted emerging real contexts. This paper aims to discuss potentials and possible shortcomings of the living lab approach $[2,3]$ see also information box) in filling this research gap.
Our specific research interest is mobile participation (m-participation) in urban governance, which we have set out to explore by way of a living lab approach in the multidisciplinary project 'Building Pervasive Participation' (b-Part). The idea of place-based mobile participation has gained most interest in studies on human-computer interaction (HCI), in which the concept "pervasive" refers to the technology mediated possibility to participate at any given time and place. In practice, researchers experimenting the possibilities of mobile technologies have raised important notions of situated engagement [4], participatory sensing [5], and gamification [6] in supporting participation. Recently, after experiments have started to spread, the discussion on mobile participation is emerging also in social sciences, in connection with government innovation [7] and participatory planning [8,9], pondering social and political impacts of new technologies. The "situated engagement" [4] participating at the locations participants are supposed to reflect upon - is believed to be the game changer: being present in the place (in-situ), physically close to the planning object (or other subject of participation), is likely to result in richer and more detailed observations than ex-situ (remote) participation.

\section{Positioning the Living Lab Approach} The living lab approach offers unique potential in combining the access to state-of-the-art technologies (through research involvement) and contextualization (through implementations in real-world-environments). 
Table 1. The role of researchers and the context of research

\begin{tabular}{|l|l|l|}
\hline & $\begin{array}{l}\text { Single } \\
\text { controlled } \\
\text { context }\end{array}$ & $\begin{array}{l}\text { Multiple and } \\
\text { emerging } \\
\text { contexts }\end{array}$ \\
\hline $\begin{array}{l}\text { Research } \\
\text { observation } \\
\text { and creation }\end{array}$ & $\begin{array}{l}\text { Traditional Lab } \\
\text { Experimentation }\end{array}$ & $\begin{array}{l}\text { Living Lab } \\
\text { Experimentation }\end{array}$ \\
\hline $\begin{array}{l}\text { Research } \\
\text { observation }\end{array}$ & $\begin{array}{l}\text { Traditional } \\
\text { Quantitative } \\
\text { Social Science } \\
\text { Research }\end{array}$ & $\begin{array}{l}\text { Traditional } \\
\text { Qualitative Social } \\
\text { Science Research }\end{array}$ \\
\hline \multicolumn{2}{|l}{} \\
\hline
\end{tabular}

Having access to state-of-the-art technologies is a first key aspect. In democracy studies, a considerable number of case studies of online consultations have been carried out in recent years - using both qualitative and quantitative research methods. While these have studied participation in natural, multiple and emerging contexts, they have rarely based on the latest technology and have tended to be poorly designed [11]. This comes as no surprise. Local government is the context where experimentation primarily takes place, if at all [12]. The problem with this laboratory is that emerging technologies are not tested, due to low local technological capacity and little research

involvement.

Access to real decision-making processes is a second key aspect. While traditional lab experimentation may have access to state-of-the-art technologies, this approach hinders researchers from moving beyond the study of small group interactions. Attention is also required as to how those interactions relate to the larger political institutions, which in turn is a matter of paramount importance to making the research relevant for societal development [13]. Since political participation is ultimately about power, we also know that people are willing to participate in field tests only if the initiative is connected with policy-making [12]. The capacity of the traditional lab experiments is thus limited. It does not reach to examine who participates and towards understanding interaction between politicians, experts, and citizens within the political system.

Fulfilling the potential of living labs is, however, challenging. Especially the contextualization part, which is both resource-intensive and requires special competences. This is why there are still few living lab studies that provide serious context research, which has even raised the question whether they actually reflect real users in real-world-environments [3]. The context will therefore be the focal point of describing our living lab. First, however, we will shortly describe our mobile participation application Täsä, developed in our research project (b-Part), and experimented in and studied through the living lab.

\section{Täsä application for mobile participation, research and development}

The mobile application Täsä (here) is tested in a living lab run in cooperation with the City of Turku (Finland), between June and September 2015. The app allows citizens and city officials to introduce and discuss placebased urban development issues by posting georeferenced content. Participants can add ideas, indicate problems, and create surveys. The app allows for both 
the municipality and citizen to initiate participation and eventually to co-create urban policy ideas.

For the users, the app is a participation tool. In addition, for the researchers, it is a tool for collecting research data. Each user entry is saved in a database together with e.g. the geo-location it was posted, which enables the researchers to study situated engagement. Since the app includes both tasks initiated by the municipality and by citizens, it enables comparisons of top-down and bottom-up participation. Moreover, additional data is collected with pre- and post-surveys among the registered participants, which resembles a semi-experiment. For instance possible changes in democracy attitudes are tested this way.

\section{Connecting with multiple political contexts}

A close partnership with the City of Turku (the municipality) has been necessary considering its authority in implementing citizen's planning suggestions and ideas. During the living lab, Täsä has received formal status, thus becoming one official participation channel of the municipality. The partnership with the municipality has included workshops to select initial questions to be addressed through m-participation; co-operation on how tasks are formulated in the app; coordinating the role of commenting citizen input; and negotiating how the results of citizens' inputs should be integrated in the formal policy process. The municipality's communications department has also provided valuable help in marketing the app.

Although the co-operation with the municipality has run smoothly, it has not been entirely challenge free. Much of this has to do with the yet-developing position of citizen participation in urban governance [14]. As part of the research project, the team conducted interviews with key planners and policy-makers of the municipality. These interviews revealed a generally positive normative attitude towards participatory governance, but also a fear that increased citizen participation in the planning process would increase their workload considerably. Hence, increased citizen engagement could easily conflict with competing organizational goals, such as (current consideration of) efficiency. This reveals an ambivalent attitude towards citizen participation. In our project, the ambivalence has manifested in two ways. First, once asked to propose tasks, most planners have not, intentionally or not, brought up conflictual issues. Most tasks were easy-going development issues, like indicating places that would require new bicycle parking. Such tasks, while relevant per se, do not touch any politically sensitive issues, such as power inequalities in setting priorities in urban development or built heritage conflicts, for instance. Secondly, the hesitation towards "too much participation" has been brought up in selecting or not some cases, revealing prejudices concerning the usefulness of citizen input.

In the preparation phase of the living lab, the citizens were involved in two "walkshops" [15] to test the prototype versions of the application. The first walkshop targeted neighbourhood association activists, and the second one students of an urban geography course. The first and a planned, but unrealised, third walkshop showed how difficult it was to motivate people to test a beta-technology and share informed opinions without an explicit connection to the policy process. 
Once the living lab has started (two weeks before writing this paper), two challenges have surfaced. First, there are technological challenges, or usability issues, in relation to what might be called still a beta-version of the application. Usability has proven a major issue among those early-users eager to try the new application - not to mention the public at large. Even if the app has received considerable media attention and many people have downloaded it, the actual usage has been low, with many users presumably annoyed by the usability issues. Secondly, there is a political challenge on trust. Matching the attitudes among some policy makers, many citizens seem to be reluctant to share their ideas due to their suspicion that these will not be considered by the policy-makers or make a difference in the final policy outcome.

\section{Conclusions}

Using a living lab for developing mobile participation enables researchers to test the most recent technologies in real-life settings. On the one hand, emerging technology might trigger unexpected challenges, such as the usability issues. On the other hand, while living labs must, by definition, be run in a real social and political context, this call for cooperation on behalf of political institutions, which often are ambivalent towards change, including the innovation promoted and tested in a living lab. As our experiences show, the potential of the living lab approach for studying mobile participation have been vulnerable for both of these reasons.

Nonetheless, the living lab approach enables the analysis of user (and stakeholder) engagement well beyond other research settings. Additional advantage is that the living lab approach can be combined with pre- and post-evaluation, which resembles a semiexperiment. In our case, we run pre- and post-surveys among registered users of the app. The pre-survey enables awareness about the socio-demographic characteristics of the users, which is usually disregarded in the small trials of HCI research. The living lab may also offer unique research perspectives. For instance in our case, the app includes both tasks set by the municipality as well as ones created by the citizens as well as gives all users the same tools to raise and discuss issues important to them; this enables comparisons of top-down and bottom-up participation, which could hardly be conducted in another research setting.

\section{Acknowledgements}

The inter-disciplinary b-Part research project is funded by the European Commission's Joint Programming Initiative Urban Europe.

\section{References}

1. Russell J. Dalton. 2013. Citizen politics: Public opinion and political parties in advanced industrial democracies. Irvine, CA: CQ Press.

2. Yvonne Franz. 2014. Chances and Challenges for Social Urban Living Labs in Urban Research. In: ENoLL - European Network of Living Labs (2014): Conference Proceedings of Open Living Lab Days 2014.

3. Asbjørn Følstad. 2008. Living labs for innovation and development of information and communication technology: A literature review. eJOV: The Electronic Journal for Virtual Organization \& Networks, 10: 99-131.

4. Matthias Korn. 2013. Situating engagement: Ubiquitous infrastructures for in-situ civic 
engagement. PhD thesis, Aarhus University. http://pure.au.dk/portal/files/56904964/phd2013. pdf (Accessed 03.06.2015).

5. Shin'ichi Konomi, Tomoyo Sasao, Masatoshi Arikawa and Hideyuki Fujita. 2013. A mobile phone-based exploratory citizen sensing environment. Paper presented at UbiComp'13, September 8-12, 2013, Zurich, Switzerland.

6. Hitoshi Kawasaki, Atsushi Yamamoto, Hisashi Kurasawa, Hiroshi Sato, Motonori Nakamura and Ryuma Kakinuma. 2013. An evaluation of method for encouraging participation. In Adjunct Proceedings of the 2013 ACM conference on Pervasive and ubiquitous computing adjunct publication.

7. Kevin C. Desouza and Akshay Bhagwatwar. 2012. Citizen Apps to Solve Complex Urban Problems. Journal of Urban Technology, 19, 3: 107-136.

8. Titiana-Petra Ertiö and Sampo Ruoppila. 2014. Supporting 'participation' in mobile participation. In: Marijn F.W.H.A. Janssen, Frank Bannister, Olivier Glassey, Hans Jochen Scholl, Efthimios Tambouris, Maria A. Wimmer and Ann Macintosh (Eds.) Electronic Government and Electronic Participation (Innovation and the Public Sector, vol. 21). Amsterdam: IOS Press, 3-12.

9. Titiana-Petra Ertiö. 2015. Participatory Apps for Urban Planning - Space for Improvement. Planning Practice \& Research, forthcoming. http://dx.doi.org/10.1080/02697459.2015.105294
10. Mats Eriksson, Veli-Pekka Niitamo and Seija Kulkki. 2005. State-of-the-Art in Utilizing Living Labs Approach to User-centric ICT innovation - a European approach. CDT at Luleå University of Technology, Sweden, Nokia Oy, Centre for Knowledge and Innovation Research at Helsink Scholl of Economics, Finland, 2005.

11. Martin Karlsson. 2012. Democratic legitimacy and recruitment strategies in eParticipation projects. In Yannis Charalabidis and Sotirios Koussouris (Eds.) Empowering open and collaborative governance. Berlin Heidelberg: Springer, 3-20.

12. Joachim Åström and Åke Grönlund. 2012. Online consultations in Local Government: What works, when, and why? In Stephen Coleman and Peter M. Shane (Eds.) Connecting democracy: Online consultation and the flow of political communication, Boston: MIT-Press, 75-96.

13. Dennis F. Thompson. 2008. Deliberative Democratic Theory and Empirical Political Science. Annual Review of Political Science 11: 497-520.

14. Pia Bäcklund and Raine Mäntysalo. 2010. Agonism and institutional ambiguity: Ideas on democracy and the role of participation in the development of planning theory and practice - the case of Finland. Planning Theory, 9, 4: 333-350.

15. Matthias Korn and Pär-Ola Zander. (2010). From workshops to walkshops: Evaluating mobile location-based applications in realistic settings. Proceedings of OMUE Workshop at NordiCHI, 10: 29-32. 